\title{
Políticas de preservação e construção da memória urbana: o caso de Santa
}

Efigênia (SP)

Herta Franco*

\section{Resumo}

Este trabalho analisa como a memória urbana e a preservação do patrimônio edificado têm sido articuladas na região de Santa Efigênia (São Paulo). Este bairro, dos mais antigos da cidade, há décadas vem sendo alvo de ações que tentaram reverter problemas sociais e ambientais por meio de políticas culturais que envolviam diretamente o patrimônio edificado. Diante da fragilidade dessas políticas, e utilizando o instrumento da concessão urbanística, a municipalidade propôs uma intervenção mais radical, pressupondo maior liberação do solo urbano para construção de novas edificações e a valorização fundiária, de modo a garantir substituição de usos e de população. Para melhor compreensão do contexto no qual se insere o tema e o campo de tensão criado, estamos considerando a atuação dos órgãos preservacionistas, dos movimentos sociais e da Prefeitura Municipal de São Paulo. Assim, pretendemos compreender qual papel atribuído à memória e às políticas preservacionistas nos processos de intervenção urbana nas metrópoles contemporâneas, analisando o caso específico do centro da cidade de São Paulo.

Palavras-Chave: Patrimônio Edificado. Políticas Culturais. Nova Luz

\section{Preservation Policies and construction of urban memory: the case of Santa Efigênia (SP)}

This article aims to analize how the urban memory and preservation of built heritage has been articulated in the region of Santa Ifigênia (São Paulo). This neighborhood, one of the oldest in the city, for the last decades has been the target of actions that tried to reverse social and environmental problems through cultural policies involving directly the built heritage. For better understanding, we are considering the performance of conservationists, social movements and of the group that comprises the Nova Luz consortium, who was hired by PMSP to design a radical intervention in the area. By this way, we want to understand what role assigned to the policies of urban intervention processes conservationists in the contemporary metropolises, analyzing the case of São Paulo. 
Keywords: Built heritage. cultural politics. Nova Luz

\section{Esboços de um polo cultural contemporâneo e a delimitação de sua área}

Este trabalho aborda a problemática que envolve os processos de patrimonialização de bens culturais e os critérios que nortearam o tombamento de edificações na região de Santa Efigênia. Para tanto, tomamos como ponto de partida a análise da listagem de bens tombados elaborada pelo Condephaat (Conselho de Defesa do Patrimônio Histórico, Artístico e Turístico do Estado de São Paulo) e pelo Conpresp (Conselho Municipal de Preservação do Patrimônio Histórico, Cultural e Ambiental), que serviu de orientação para a elaboração de projeto proposto para concessão urbanística, conduzida pela Prefeitura Municipal de São Paulo.

A partir de pesquisa de campo e levantamento fotográfico, pudemos observar algumas características comuns entre os bens escolhidos para o tombamento. Entre eles, destaca-se a época da construção e o vínculo explícito com uma estética ligada ao ornamento, seja o ecletismo, art nouveau ou art déco. Edificações construídas posteriormente não estão sendo protegidas pelo tombamento.

Esta constatação nos leva a crer que a estratégia de proteção do patrimônio edificado em Santa Efigênia teve por objetivo a preservação de construções contemporâneas aos grandes monumentos existentes na região - entre eles a Estação da Luz, a Estação Júlio Prestes, a Pinacoteca do Estado, a antiga sede do DOPS, a Igreja de São Cristóvão, o Parque da Luz -, todos construídos ou reformados na virada dos séculos XIX e XX, fase de grande pujança da cidade em função da economia cafeeira. Tal postura parece indicar que a preservação na região é norteada pelo desejo de criar uma paisagem coerente do ponto de vista estético, na qual monumentos e edificações comuns tenham afinidades estilísticas. Para tanto, imóveis construídos posteriormente, que "destoam" do conjunto, mas que estão diretamente ligadas à história e às dinâmicas urbanas pelas quais o bairro passou ao longo do século XX, estão sendo ignoradas. 
Dado que a atuação do poder público na região da Luz/Santa Efigênia vem ocorrendo desde os anos de 1970, achamos oportuno considerar as ações atuais como desdobramento de um processo mais longo que visou transformar a área no "novo polo cultural" da cidade, polo este no qual o patrimônio edificado tem papel preponderante. O conjunto urbano monumental herdado da virada dos séculos XIXXX legitimou a preservação e a implementação de sucessivas políticas culturais que pretendiam requalificar a área do ponto de vista físico e social através da cultura, mas sendo elas frágeis e parciais, têm contribuído efetivamente para a valorização fundiária e expulsão de população de baixa renda ${ }^{1}$.

Diversas fontes foram úteis para compreendermos este percurso, entre elas os processos de tombamento $^{2}$, jornais ${ }^{3}$, revistas de especializadas e entrevistas ${ }^{4}$, o que nos permitiu constatar a complexidade do processo que envolve a intervenção na área, considerando os diversos grupos sociais atuantes. Estes têm interesses e visões de mundo muito distintas no geral, mas também no que se refere ao patrimônio e a preservação de bens culturais. Somadas às fontes textuais, foi fundamental para o trabalho a realização de pesquisa de campo, na qual pudemos fotografar diversos lotes, quadras, ruas e edificações, e comparar os bens indicados para o tombamento entre si, com os que não foram propostos. Dadas as diversas mudanças ocorridas nas listagens de tombamento ao longo do tempo, não pudemos verificar todas as construções em todas as quadras, mas focamos o trabalho em algumas situadas nas ruas do Triunfo e Santa Efigênia por concentrarem maior número de bens a serem tombados.

\section{Preservação e memória na criação de um polo cultural contemporâneo: a} delimitação da área

Os primeiros estudos sobre Santa Efigênia feitos pelo Condephaat datam de 1982, e estavam circunscritos a uma área delimitada pelas avenidas Rio Branco, São João, Duque de Caxias e rua Mauá, sendo reconhecida a relevância de 62 edificações. Uma lista foi feita dando origem ao processo de tombamento do bairro, em 1986. Nesse momento tramitava pela Prefeitura Municipal de São Paulo um projeto de intervenção entre a avenida Rio Branco, a rua de Santa Ifigênia e a rua Mauá, que visava promover o adensamento e eliminar os cortiços. Assim, o pedido de tombamento feito pelos técnicos do Condephaat pretendia atenuar os efeitos 
deste projeto que previa a demolição de grandes áreas, preservando um determinado conjunto de edificações, o traçado e a paisagem existentes, considerados importantes por materializar os usos diversos, tais como o comércio, o lazer e a habitação, em tipologias igualmente variadas, ocupados por uma população marcada pela diversidade social e cultural ao longo do século $X X$.

A urgência de ações que revertessem a situação de crise e abandono do capital público e privado no qual se encontravam as áreas urbanas centrais não se deu apenas em São Paulo. Aqui, mais uma vez, a preservação - e em última instância, o tombamento - apresentou-se como medida emergencial dada a inexistência de uma política urbana clara e eficiente que regulasse a ação do executivo e da iniciativa privada. Porém, a "revitalização" (termo usado na época) das áreas centrais era um tema muito vivo nessa década, resultando em intervenções em diversas cidades europeias e brasileiras ${ }^{5}$.

O conjunto de edificações indicadas pelo Condephat para o tombamento em 1986 pode ser dividido, em linhas gerais, em três grupos: os situados na rua do Triunfo, os da rua de Santa Efigênia e os situados nas proximidades da Estação da Luz (ruas Mauá, General Couto de Magalhães e Cásper Líbero). Nos três casos predominam as edificações ecléticas, somadas à algumas art nouveau e art déco, variando os usos (habitação, comércio, hotel) e o gabarito (entre um e quatro andares), construídas no alinhamento. Foram privilegiadas as edificações que estavam em bom estado de conservação e que apresentavam certo grau de "autenticidade". Também foram preservadas as edificações de esquina, ornamentadas e imponentes como os congêneres construídos na Paris haussmanniana. Nos arredores da Estação do Luz (rua Mauá com avenida Cásper Líbero) encontram-se os edifícios destinados à hotelaria, com dois andares, ornamentados, e construídos em grandes lotes, causando maior impacto visual. 


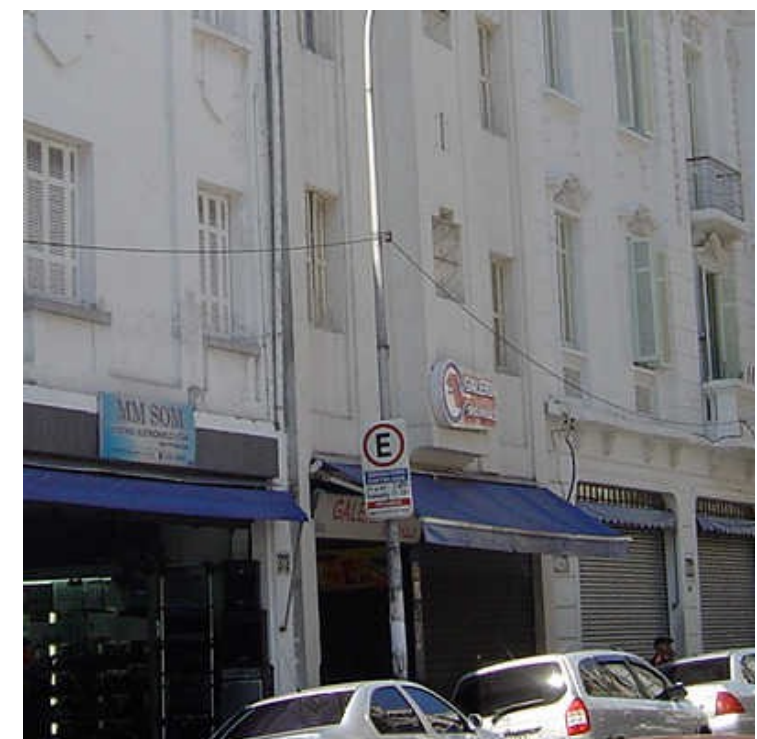

Figura 1 - Conjunto de edificações na Rua Santa Ifigênia indicadas para tombamento pelo CONDEPHAAT e pelo CONPRESP. Fonte: Acervo pessoal

A abertura do processo de tombamento pelo Condephaat foi o desdobramento de ações anteriores, que remontam ao ano de 1974. Neste, a equipe do escritório Rino Levi Arquitetos Associados realizou um estudo encomendado pela Cogep (Coordenadoria Geral de Planejamento) no contexto da inauguração da linha NorteSul do Metrô, em 1975. O projeto fazia um diagnóstico minucioso da Luz/Bom Retiro, e apresentava propostas que visavam incentivar o adensamento populacional, com a construção de habitações e a melhoria das condições de vida da população local, com a implantação de centros educacionais e de saúde. Porém, cabe aqui destacar a importância atribuída neste projeto à questão da proteção e da valorização do patrimônio arquitetônico e ambiental da região, reconhecendo seu potencial para o lazer cultural. Dada a relevância dos monumentos existentes, o projeto propunha a conversão de algumas áreas da Luz e do Bom Retiro em área de preservação, protegendo tanto edifícios isolados quanto manchas urbanas, incluindo o Parque da Luz, a Igreja de São Cristóvão e as Vilas Economizadoras e Inglesa.

$\mathrm{Na}$ prática, contudo, o plano foi desconsiderado no que se referia às propostas voltadas ao aumento da densidade demográfica e nas melhorias para os bairros. Mas o levantamento dos bens culturais possibilitou a abertura dos processos de tombamento de alguns monumentos, entre eles, a Pinacoteca do Estado e a Estação da Luz, que vieram a ser tombados efetivamente em 1982. 
A postura adotada no projeto demonstra a incorporação do conceito de cultura em seu sentido antropológico, considerando-a como modo de vida que compreende saberes, costumes e práticas cotidianas da coletividade. Nesta visão a cidade é abordada como um documento ou um artefato relevante como patrimônio cultural coletivo. Demonstra ainda uma ampliação do conceito de cultura, e consequentemente de patrimônio, muito discutida durante os anos de 1970, e que reconhece valor não somente nas obras de caráter excepcional, monumental ou memorável do ponto de vista do valor histórico. Tal mudança teve, entre outros desdobramentos, alterações no campo de ação dos órgãos preservacionistas e de seus profissionais, cuja atuação até então estava restrita apenas ao patrimônio edificado, legitimado pela história da arte ou por questões técnicas. É quando se coloca em pauta a discussão em torno do patrimônio tangível e intangível, o que pensando nas cidades, implica a criação de políticas de preservação que contemplam a recuperação das construções, mas também de aspectos socioculturais correlatos.

Ainda com o intento de "revitalizar" os bairros da Luz/Bom Retiro por meio da cultura, em 1984, a Secretaria Municipal de Cultura conduziu um trabalho voltado especificamente para a dinamização da área, visando integrar os espaços públicos e institucionais com a população local através do Projeto Luz Cultural. A iniciativa envolvia a área entre o rio Tamanduateí, a avenida. Rio Branco e a rua Mauá, incluindo os quarteirões adjacentes a este perímetro, propondo a criação de laços entre a comunidade e a região. Já apoiado no discurso da "valorização do espaço público", o projeto pressupunha que o contato da população local com os bens culturais, por si só, promoveriam uma "renovação urbana". O Projeto Luz Cultural teve a Oficina Cultural Oswald de Andrade como base, e propunha parcerias com a Polícia Militar, com a Secretaria Estadual de Cultura e com a Pinacoteca do Estado que, apesar de efetivadas, não duraram muito tempo.

Nessas primeiras tentativas de requalificação, percebe-se que a área da Luz limitada pela barreira urbana imposta pela linha férrea - estava separada de Santa Efigênia. Eram bairros distintos ${ }^{6}$, com nomes, usos, e dinâmicas urbanas diferentes, em função da História e das diversas fases de ocupação dos bairros ${ }^{7}$. 


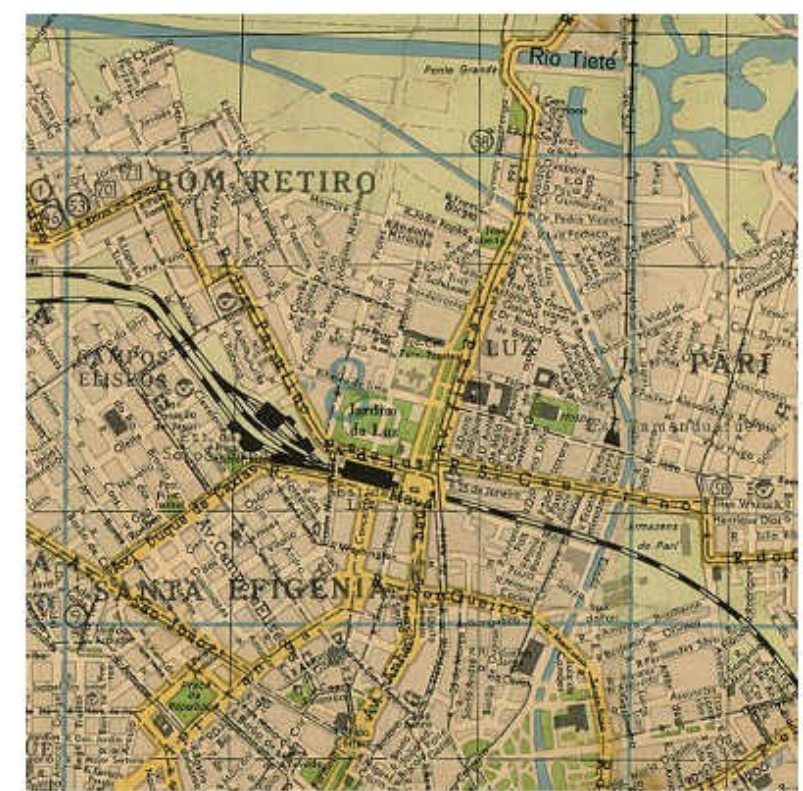

Figura 2 - Mapa identificando a localização dos bairros na região da Luz, em 1951. São Paulo; Cia Melhoramentos de São Paulo, 1951, escala: 1:25.000- 1: 40.000. Fonte: Acervo Instituto Geográfico e Cartográfico de São Paulo.

Ao longo dos anos de 1990 foi dada continuidade aos estudos para o tombamento de Santa Efigênia, porém mudanças significativas ocorreram nas políticas de preservação empreendidas pela Secretaria de Estado da Cultura na região. Ainda pautada pela crença no potencial de "revitalização urbana" promovida por atividades culturais, foram criadas ou reformadas instituições de grande porte nos edifícios monumentais existentes (alguns tombados nos anos de 1980), entre eles, a Pinacoteca do Estado (1996-1998), o Complexo Cultural Júlio Prestes e a Sala São Paulo (1996-1999), o Museu de Arte Sacra e o Mosteiro da Luz (1997-1999), o Jardim da Luz (1999), a Igreja de São Cristóvão (1995-2001), a Universidade Livre de Música, o antigo prédio do DOPS, convertido em Estação Pinacoteca e Memorial da Resistência (2002) e o Museu da Língua Portuguesa (2006) na antiga Estação da Luz. No geral foram realizadas intervenções drásticas nesses edifícios, até mesmo questionáveis do ponto de vista da preservação de um bem cultural, como o ocorrido na Pinacoteca do Estado e na Estação Pinacoteca ${ }^{8}$. A intenção era converter tais edifícios monumentais em "âncoras culturais", de grande apelo midiático, capazes de atrair grande volume de visitantes, provenientes de outras áreas da cidade, e com perfil sociocultural distinto dos moradores da região. A configuração de um novo eixo cultural para a cidade na Luz se tornou ainda mais factível a partir de 1995, quando a então Secretaria de Transportes Metropolitanos começou a articular o 
Programa Integrado de Transportes Urbanos (Kara-José; 2007). Com a integração das estações de trem metropolitano ao metrô na Estação da Luz, esta se tornou fundamental para o sistema de transporte coletivo da metrópole, facilitando o acesso aos diversos equipamentos culturais existentes na região ${ }^{9}$.

A iniciativa consolidou-se no final dos anos de 1990 quando foi proposta a criação de um novo polo cultural para a cidade através do projeto "Polo Cultural Luz", como parte de um conjunto de tentativas que visavam "revitalizar" o centro da cidade. Cabe lembrar que desde os anos de 1950 diversos museus e espaços culturais, entre eles, o MASP e o conjunto do Parque do Ibirapuera, foram criados no quadrantes sul e oeste da cidade, fazendo com que as atividades "culturais" mais prestigiadas se retirassem do Centro.

O projeto abrangia a área delimitada pelas avenidas Tiradentes e Prestes Maia, no eixo norte-sul; a avenida Duque de Caxias e a rua Mauá, na vertente sul; a alameda Nothmann, a oeste; e a rua Três Rios ao norte. O plano atingia a área de Santa Efigênia e apontava a urgência para a solução de problemas sociais existentes ali, sobretudo os relativos a habitação, dada a existência de cortiços em diversas ruas do Polo. Porém, soluções específicas para esta questão não foram apontadas.

Viu-se que, com a instalação das "âncoras culturais", a região passou a atrair grupos sociais e interesses políticos e econômicos distintos dos que eram predominantes até então. Área extremamente dinâmica do ponto de vista comercial, com eixos comerciais referenciais como a rua José Paulino (moda) e a rua Santa Efigênia (eletroeletrônicos e motos), há décadas foi sendo abandonada por grupos abastados da cidade para o uso residencial, atraindo segmentos sociais de baixo poder aquisitivo. Estes se instalaram no Centro em busca da boa infraestrutura de transporte existente e dos aluguéis relativamente baratos, resultantes das diversas formas de precarização da habitação multifamiliar, sobretudo os cortiços. Sendo considerados incompatíveis com um bairro voltado para a atividades culturais, estas entendidas como lazer e entretenimento voltados para camadas médias e altas, viuse nesses anos o abandono de projetos e de diretrizes de políticas de habitação de interesse social que estavam sendo delineadas e implementadas no Centro como todo (KARA-JOSE, 2007), e em particular na Luz/ Santa Efigênia. 
O projeto do "Polo Luz Cultural" foi encomendado pela Associação Viva O Centro, organização social criada em 1991 que, desde 1995, tem apresentado a todos os prefeitos um conjunto de propostas para o centro da cidade, propostas estas que estão em sintonia com seus associados, na maioria bancos e outras grandes empresas ligadas ao terciário. Cabe lembrar que a estabilidade desta instituição diante das mudanças periódicas no poder executivo, somadas à elaboração de planos e ao poder de pressão política e econômica de seus associados, tem feito da Associação Viva o Centro um agente de importância crescente na configuração do centro da metrópole, ao qual se tem subordinado o poder público.

Considerando o exposto, o projeto Polo Luz Cultural pode ser entendido também como um desdobramento da Operação Urbana Centro, aprovada em 1997, cujos objetivos eram, entre outros, reforçar a importância da área central para a metrópole, atraindo investimentos no setor imobiliário, turístico e cultural, o que indica a aplicação de políticas culturais apoiadas na preservação do patrimônio edificado e de um conjunto de práticas que visavam a valorização fundiária e simbólica da região, de modo a atrair para o Centro grupos sociais de maior poder aquisitivo, e repelir os mais pobres.

Assim, concomitante aos estudos para o tombamento de Santa Efigênia deu-se a implementação de nova política cultural e urbana, pautada pela criação de grandes equipamentos culturais em edifícios tombados, custeados por parcerias entre o poder público e a iniciativa privada. Esta, fazendo uso da Lei Federal de Incentivo à Cultura (Lei n. 8.313, de 1991), e das congêneres criadas pelos governos estadual e municipal, passaram a investir em ações culturais, entre elas as relacionadas à preservação e divulgação do patrimônio cultural brasileiro, inclusive o edificado ${ }^{10}$.

Um novo modelo de gestão foi implementado para administrar estes bens culturais com a criação das OS. (Organizações Sociais) e das Oscips (Organizações da Sociedade Civil de Interesse Público), decorrentes da Reforma do Estado no Brasil, iniciada em 1995 pelo Ministério da Administração e Reforma do Estado. Subordinadas à Secretaria Estadual de Cultura, estas instituições representam novo modelo de gestão de serviços públicos no qual o Estado delega a grupos 
selecionados a condução de instituições públicas e de seu patrimônio. Cabe lembrar que quatro instituições instaladas na região da Luz/ Santa Efigênia neste período, ou seja, a Sala São Paulo, a Pinacoteca do Estado, o Museu da Língua Portuguesa e a Universidade Livre de Música são administradas por este modelo de gestão ${ }^{11}$.

O caráter ideológico desse processo, que se configura no bojo do ideário neoliberal e da terceirização da economia, no qual a cultura ganha um papel de destaque no planejamento e na intervenção nas cidades contemporâneas, vem sendo discutido nos escritos de Otília Arantes. Nas últimas décadas, a filósofa tem-se debruçado sobre os fundamentos e os efeitos do planejamento estratégico nas cidades contemporâneas, apontando o papel relevante atribuído à cultura neste modelo urbanístico. Apresentado como um conjunto de práticas de produção e gestão do espaço urbano compatíveis com a versão contemporânea do capitalismo, o planejamento estratégico é um desdobramento da crise do Estado de Bem-Estar Social e do planejamento urbano, que pressupõe o crescimento exponencial do capital privado, que se torna voraz na busca por novos pontos de investimento e de reprodução. Esta condição faz das cidades, principalmente as metrópoles, polos privilegiados de aplicação, sendo vista por seus ideólogos como uma "máquina de produzir renda"12 por meio de intervenções em áreas consideradas decadentes, sobretudo as pauperizadas pela crise industrial. No ímpeto de "recuperar" áreas supostamente degradadas, a aplicação do planejamento estratégico se converte em instrumento para o enobrecimento urbano, sobretudo quando a "recuperação" de uma área se dá pela adoção da cultura com "carro-chefe". Com a redução dos investimentos públicos em políticas sociais, em função da crise do Estado de Bemestar Social, estes recursos passam a ser voltados significativamente para a cultura, cabendo a esta um papel fundamental na reprodução do capitalismo contemporâneo, segundo a autora. Nas mais variadas escalas, o patrimônio e a restauração contribuem para a "criação de imagens publicitárias", imagens estas que, compartilhadas no âmbito local e internacional, aumentam o fluxo de visitantes, desejosos de conhecer de perto os locais amplamente divulgados.

Este ideário, formulado como solução para a crise da cidade industrial, aborda a cultura como instrumento de desenvolvimento econômico, dando margem a formulação de conceitos como o de "economia criativa". Associada ao turismo, a 
cultura passa a ter papel fundamental na sociedade de consumo, na qual a vivência e a experiência em espaços urbanos valorizados conferem reconhecimento e prestígio. Isso indica que as intervenções realizadas na cidade têm uma dimensão física e territorial, mas também simbólica, e de grande valor na acirrada disputa por investimentos, turistas e empresas entre as principais cidades do mundo.

É neste contexto mais amplo de "culturalização" do planejamento urbano contemporâneo que propomos a reflexão sobre o papel exercido pelo patrimônio cultural no processo de requalificação urbana na região da Luz/Santa Ifigênia, sobretudo acompanhando a atuação do Condephaat e Conpresp (Conselho Municipal de Preservação do Patrimônio Histórico, Cultural e Ambiental da Cidade de São Paulo), órgãos responsáveis pela preservação do patrimônio a nível estadual e municipal, respectivamente.

\section{Patrimônio edificado e intervenção urbana: o projeto Nova Luz}

Os anos de 2000 possibilitaram mudanças significativas nas diretrizes apontadas para Santa Efigênia até então. O impacto das "âncoras culturais" criadas na década anterior junto à população local e seu suposto potencial de "regeneração urbana" foi muito menor do que o apregoado por seus defensores. Se por um lado o Museu da Língua Portuguesa - fruto da parceria entre a Secretaria Estadual de Cultura e a Fundação Roberto Marinho -, via incentivo fiscal, tornou-se um dos museus mais visitados da cidade, recebendo e criando programas educativos voltados, inclusive , para os moradores da região, os outros equipamentos não tiveram o mesmo destino. A Sala São Paulo, parceria da Associação Viva o Centro e a Secretaria de Estado da Cultura, um empreendimento considerado bem-sucedido do ponto de vista arquitetônico, tem uma relação muito restrita (ou quase nula) com o entorno, tanto do ponto de vista físico quanto humano. Com o fechamento das portas voltadas para a Praça Júlio Prestes, e acessos restritos à entrada lateral e ao estacionamento, o conjunto, que também abriga a Secretaria Estadual de Cultura, é vivenciado por frequentadores provenientes de outras áreas da cidade, apartada da população local. Apesar de diversos programas educativos serem oferecidos pela instituição, nenhum é focado no trabalho com os moradores dos bairros próximos, Santa Efigênia inclusive, o que consolida seu isolamento e sua incapacidade em promover transformações consistentes nos arredores, contradizendo a hipótese de que a 
transformação de bens tombados em equipamentos culturais tem a capacidade de requalificar áreas urbanas degradadas.

O recrudescimento dos problemas sociais e a difusão do planejamento estratégico como solução criaram condições para a formulação do projeto Nova Luz. Formalizado em 2005, o projeto estava, primeiramente, circunscrito à área que compreende as avenidas Rio Branco, Duque de Caxias, Mauá, Cásper Líbero, Praça Alfredo Issa e Avenida Ipiranga, envolvendo então 23 quadras, totalizando 250 mil metros quadrados, e atingia aproximadamente 1500 imóveis, com o objetivo de estimular um "conjunto de ações combinadas de conservação e de renovação de espaços públicos e privados na área da Nova Luz, correspondente ao perímetro de abrangência da Lei de Incentivos Seletivos, Lei n.14.096, de 8 de dezembro de 2005"13. O projeto pretendia ainda promover o aumento da densidade na região através da substituição de edificações e da verticalização, de modo a atrair novas habitações e habitantes de maior poder aquisitivo, e empresas de grande capital (por meio de incentivo fiscal), substituindo as empresas existentes. Ou seja, diferente das ações anteriores que tentaram requalificar a região da Luz/Santa Efigênia com atividades ligadas à cultura, o Nova Luz tinha objetivos e estratégias voltadas diretamente à valorização fundiária, e, consequentemente, à substituição de população. Porém, as ações propostas e os agentes envolvidos seriam diretamente beneficiados pela existência dos equipamentos culturais criados anteriormente, sobretudo investidores e moradores que o projeto pretendia atrair, entre eles, profissionais liberais, professores, funcionários públicos, estudantes, seguindo o perfil dos típicos "consumidores de cultura", denominados pelo projeto como "pioneiros".

Porém, apesar do incentivo fiscal, poucas empresas se interessaram em se instalar na região em função de problemas existentes. Alguns motivos que explicariam esta rejeição poderiam ser citados. Um deles seria a inexistência de uma política de preservação clara, com critérios bem definidos, e bem divulgados, política esta que estivesse firmemente vinculada ao planejamento urbano e a políticas sociais eficazes. O vazio criado por esta situação se manifestava pela lentidão na resolução do processo de tombamento, que criou grande indefinição nas últimas décadas, acelerando o processo de degradação física e desvalorização dos imóveis de Santa 
Efigênia, já que os proprietários não se viam estimulados a reformá-los ${ }^{14}$. Mesmo a venda dos imóveis era difícil, tanto pelo tombamento inconcluso quanto por irregularidades na documentação dos imóveis, que são muito antigos.

Durante esses anos foi dada continuidade aos estudos para o processo de tombamento feito pelo Condephaat, cuja abrangência foi revista em 2007, em conjunto com o Conpresp, sendo alguns edifícios acrescentados a uma lista de bens passíveis de tombamento. Para elaboração desta lista procurou-se privilegiar exemplos significativos das diversas formas de morar que existiam na região, seu estado de conservação e a integridade das edificações. Acreditava-se que, com tal medida, estaria garantida a preservação de cerca de 99 imóveis, confirmando o reconhecimento da importância destas construções e do conjunto urbano.

Porém, entre 2008 e 2009, uma "revisão dos tombamentos do bairro foi feita a pedido da Prefeitura assim que Sayad (João Sayad, Secretário Estadual de Cultura de então) assumiu a pasta, no início da gestão José Serra (PSDB), em 2007. O argumento era que a preservação dos imóveis poderia inviabilizar o projeto de revitalização, a ser feito pela iniciativa privada" ${ }^{\prime 1}$. Esta revisão resultou na exclusão total de treze móveis anteriormente considerados relevantes, restando 86 imóveis da lista anterior. Destes, apenas três imóveis permanecem totalmente preservados, sendo eles, a igreja de Santa Ifigênia, a Igreja Luterana e o viaduto de Santa Ifigênia. Na listagem anterior estava prevista a preservação integral de 48 imóveis. Os outros 83 restantes têm garantida a preservação parcial, que envolve a fachada, a cobertura e alguns elementos arquitetônicos.

A justificativa para redução da lista de bens tombados foi dada pela diretora do Condephaat quando da publicação no Diário Oficial, em fevereiro de 2010. Segundo ela, "A cidade de São Paulo tem um dinamismo econômico e urbano. Não cabe ao patrimônio histórico impedir. Pelo contrário, ele deve estabelecer regras que contribuam para o desenvolvimento" ${ }^{16}$. Com essas alterações, apenas cerca de $10 \%$ da área total prevista para a implementação do projeto fica protegida pelo tombamento ${ }^{17}$.

No que se refere ao patrimônio, partindo de estudos prévios feitos pelo Condephaat, o plano classificava e hierarquizava as edificações existentes na região, apontando 
os imóveis que deveriam ser conservados por serem tombados ou por serem considerados de interesse, e a demolição para os que já se encontravam descaracterizados. Estes liberariam espaço para novas edificações que seriam controladas em seu gabarito e volumetria, assegurando recuos que não ocultassem as edificações históricas. Já os edifícios em mau estado de conservação, ou seriam demolidos ou passariam por reformas, particularmente os que tivessem uso residencial.

No projeto consolidado divulgado em agosto de 2011 foram feitas referências mais explícitas sobre o encaminhamento a ser dado para os bens tombados em Santa Efigênia. Pranchas explicativas mostram as fachadas dos bens tombados, em sua maioria ligados à estética do ecletismo, ou outras vertentes do século final XIX e início do século $\mathrm{XX}$, sobretudo o art nouveau e o art déco, comparadas às edificações que seriam mantidas pelo projeto, mas que não são protegidas pela legislação. Estas são edificações que não evidenciam ligação com a questão do "estilo", ou se aproximam das estéticas modernistas, com formas mais simples e regulares.

$\mathrm{Na}$ apresentação feita pelo consórcio Nova Luz é destacada a relevância das edificações de esquina, sobretudo o conjunto localizado na esquina da rua de Santa Ifigênia com rua Aurora, considerando-o "ativos importantes para a criação de uma identidade específica para a área". As mesmas características e potencialidades foram atribuídas pelo projeto para o conjunto de edificações situadas ao lado da Estação da Luz, "representando um importante exemplo da arquitetura residencial do final do século XIX. São sobrados que compõem, juntamente com a Estação da Luz, uma importante evidência do ambiente urbano da época em que a Estação foi construída"18.

Outros edifícios foram acrescentados à listagem de bens a serem tombados pelo Conpresp quando da ampliação do perímetro do projeto Nova Luz até a avenida São João, divulgada em 2010. Trata-se de edificações localizadas nas avenidas São João e alameda Barão de Limeira que formam conjuntos imponentes, seguindo a estética do ecletismo presente nos bulevares parisienses da segunda metade do 
século XIX. São construções de cinco a sete andares, com usos variados (hotel, habitação e/ou comércio), situados no alinhamento ${ }^{19}$.

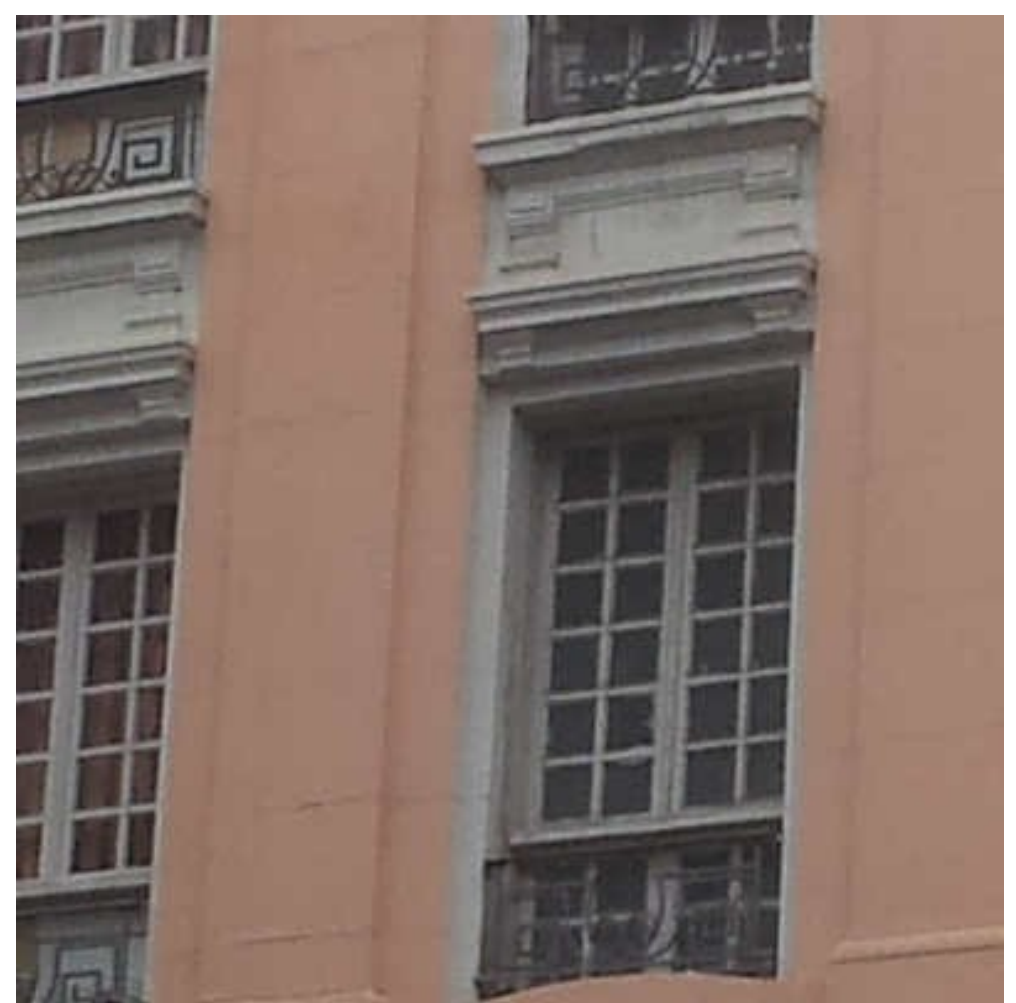

Figura 3 - Edifício situado na alameda Barão de Limeira indicado para tombamento pelo CONPRESP. Fonte: Acervo pessoal

A intenção de criar um "conjunto harmonioso" implica a valorização de edificações que tenham sido construídas no final do século XIX e começo do século XX, e que apresentem características formais semelhantes, mesmo que superficialmente, com os monumentos tombados na região, desconsiderando as edificações realizadas posteriormente. Tal postura implica o esquecimento ou abandono de outras construções que, do ponto de vista estético, construtivo, afetivo, histórico ou social, possam ser consideradas relevantes para os moradores ou para o restante da cidade, o que permite questionar a validade, a pertinência e a representatividade dos critérios adotados para o tombamento.

\section{A construção da memória e do esquecimento}

Porém, muita coisa aconteceu no bairro de Santa Ifigênia a partir dos anos de 1930. E essas mudanças se materializaram nos edifícios construídos a partir de então, e 
que não foram protegidos pela proposta do Condephaat nem pelo Conpresp, já que não foram considerados patrimônio relevante para a memória da cidade. São edifícios ligados às linguagens arquitetônicas de períodos posteriores, como o art déco, em imóveis multifamiliares, ou outras vertentes do modernismo, muitos deles com mais de oito ou dez andares, demonstrando a verticalização da área como uma alternativa para o intenso processo de urbanização pelo qual a cidade passou nesse período.

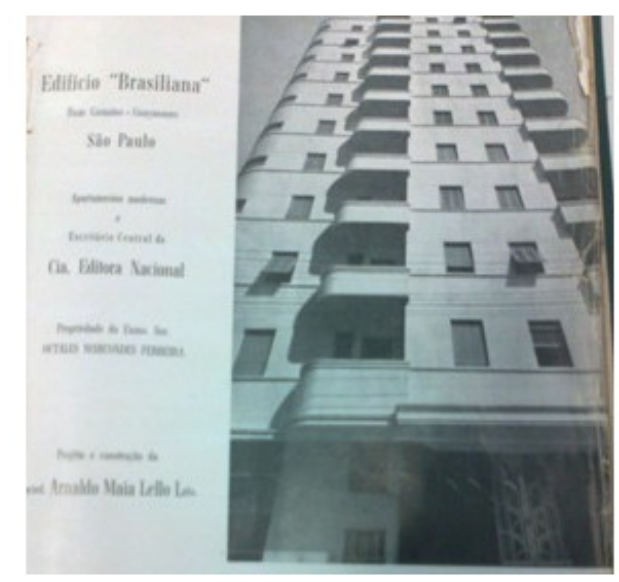

Figura 4 - Fachada e vista lateral do edifício Brasiliana, localizado na esquina da rua dos Gusmões com Guaianases. Fonte: Revista Acrópole.São Paulo (36), 1941, p.427

É a partir dos anos de 1950, concomitante ao processo de metropolização da cidade, que o bairro passou a apresentar outras atividades econômicas e sociabilidades. Desde os anos de 1920, atraídas pela estação de trem para o escoamento da produção para o interior, diversas empresas ligadas à indústria cultural como agências de publicidade, emissoras de rádio, estúdios de gravação, produtoras de cinema, oficinas para conserto de equipamentos audiovisuais e a própria "Cinelândia" já vinham se instalando na região. Esse processo permitiu a aglutinação de profissionais de rádio, televisão e cinema, ligados aos primórdios da indústria cultural na cidade que, ainda incipiente, demonstrava certo amadorismo, improvisação, criatividade e instabilidade. 


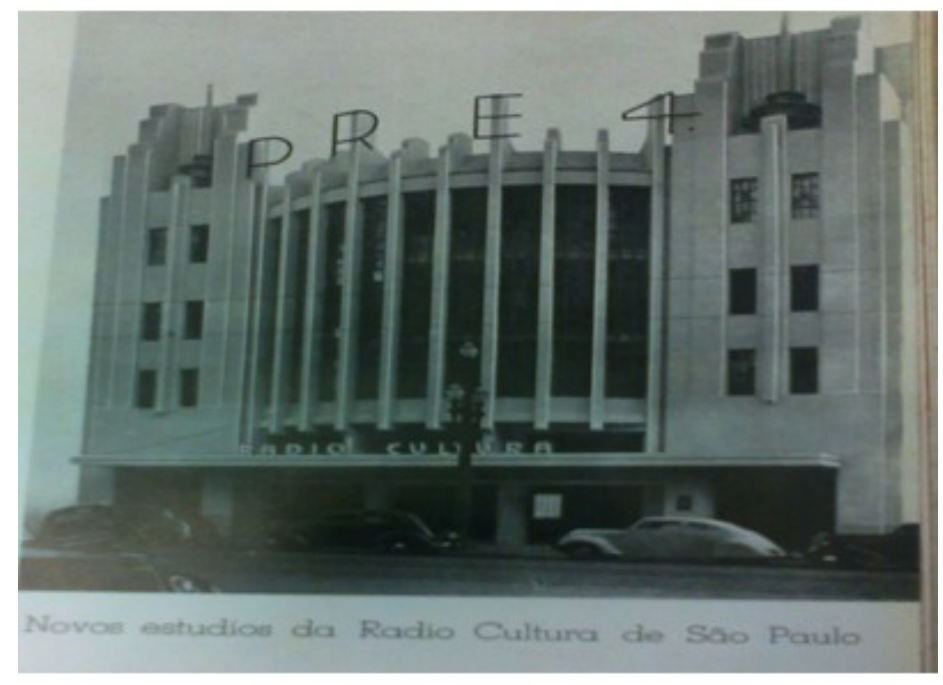

Figura 5 - Fachada principal dos estúdios da Rádio Cultura, em 1939, confirmando a tendência da região para sediar empresas ligadas à indústria cultural.

Fonte: Revista Acrópole. São Paulo (sn), maio 1939

Foi nesse contexto que, no final dos anos de 1960 e 1970, se desenvolveu uma intensa produção cinematográfica que passou a ser denominada como "cinema da Boca do Lixo", ou "cinema marginal". Diversos diretores envolvidos apontam que não havia uma característica estética ou movimento que permeasse esta produção, caracterizada pela diversidade. $\mathrm{O}$ que os unia era o fato de realizarem filmes com recursos privados, em pouco tempo, e abordando temáticas ditas "populares", seguindo a tradição das chanchadas. Mas, aproveitando o contexto de liberação dos costumes, foram, lentamente, incorporando a temática sexual, dando origem ao gênero da pornochanchada. Este passou a ser, mesmo que de uma forma generalizada, apressada e pejorativa por parte da crítica, associada ao cinema da "rua do Triunfo", principal ponto de concentração da "comunidade", que envolvia técnicos, diretores como David Cardoso, Tony Vieira, Ozualdo Candeias, Rogério Sgarzela, Carlos Reichenbach e Jean Garret, e atores/atrizes como Matilde Mastrangi, Helena Ramos, Aldine Muller, Anselmo Duarte, entre outros. 

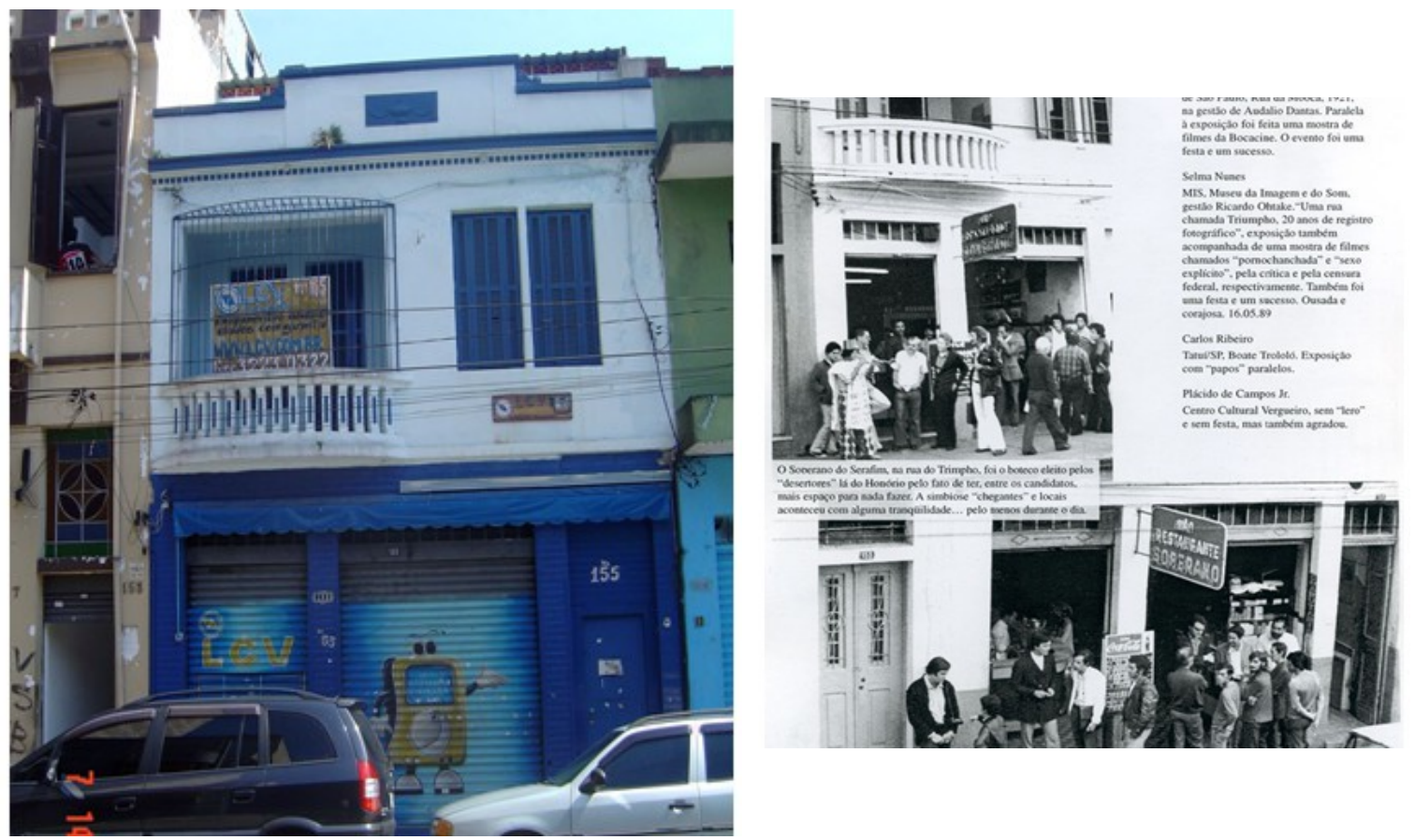

Figuras 6 e 7 - Fachada do Bar Soberano em fotos de 2009 e nos anos 70. Era o principal reduto e ponto de encontro de cineastas, técnicos e atores ligados ao cinema da "Boca do Lixo" . Esta edificação não foi indicada para o tombamento. Fonte figura n. 7: CANDEIAS, Ozualdo. Uma rua chamada Triunfo. São Paulo: ed. do autor, 2001. Fonte Figura n. 6: Acervo pessoal

A eles se misturavam os transeuntes do bairro - que desde os anos de 1960 passou a abrigar também a estação rodoviária da cidade, atraindo ainda mais migrantes de diversas regiões do Estado e do país - que se instalavam por ali nas pensões e hotéis econômicos, usufruindo da proximidade com o Centro. É nesse período que os bairros da Luz, Santa Ifigênia e Campos Elíseos se consolidam como uma área decadente e perigosa, por concentrar uma população de baixa renda, o meretrício e a criminalidade, justificando a denominação de "Boca do Lixo". Tal realidade era fruto de um processo de urbanização acelerado e avassalador, da inexistência de planejamento e de políticas sociais adequadas, somados ao autoritarismo da ditatura militar e à corrupção, realidade que se manifestava plenamente em Santa Efigênia, e que foi retratada em alguns dos filmes produzidos na região, entre eles $O$ Bandido da Luz Vermelha de Rogério Sgarzela, e, de um modo mais experimental, por Ozualdo Candeias, em Meu nome é Tonho. 


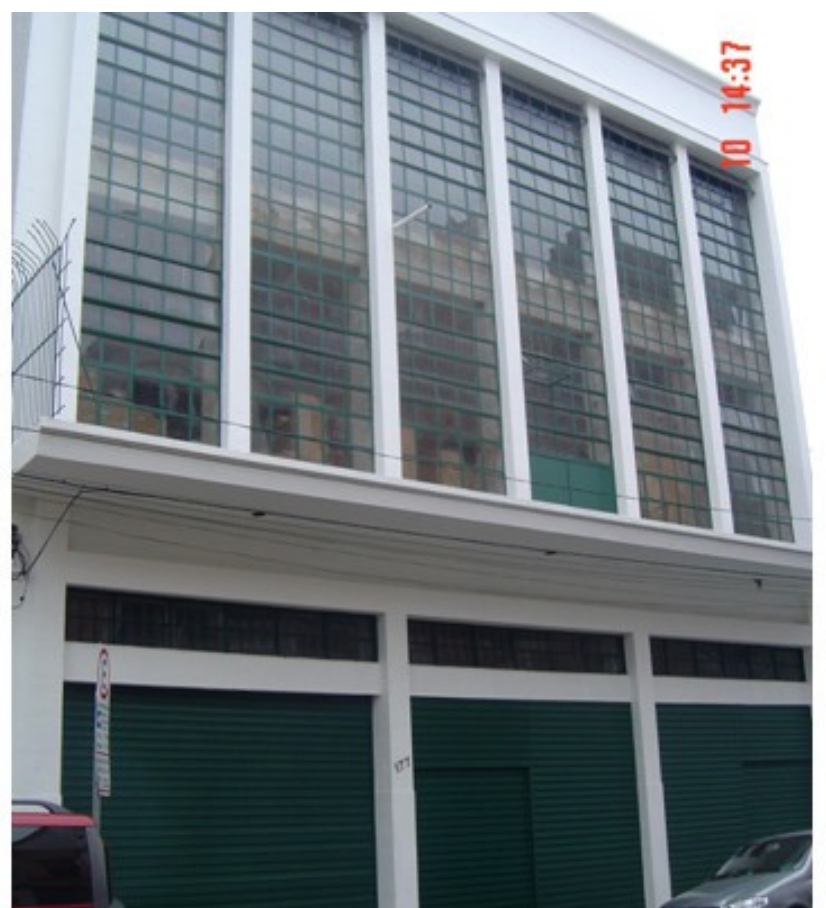

Figura 8 - Edifício no qual se instalou a filial da gravadora Polydor, entre os anos 60 e 70, e hoje é filial da Editora Paz e Terra, na rua do Triunfo. Edifício não foi indicado para tombamento. Fonte: Acervo pessoal
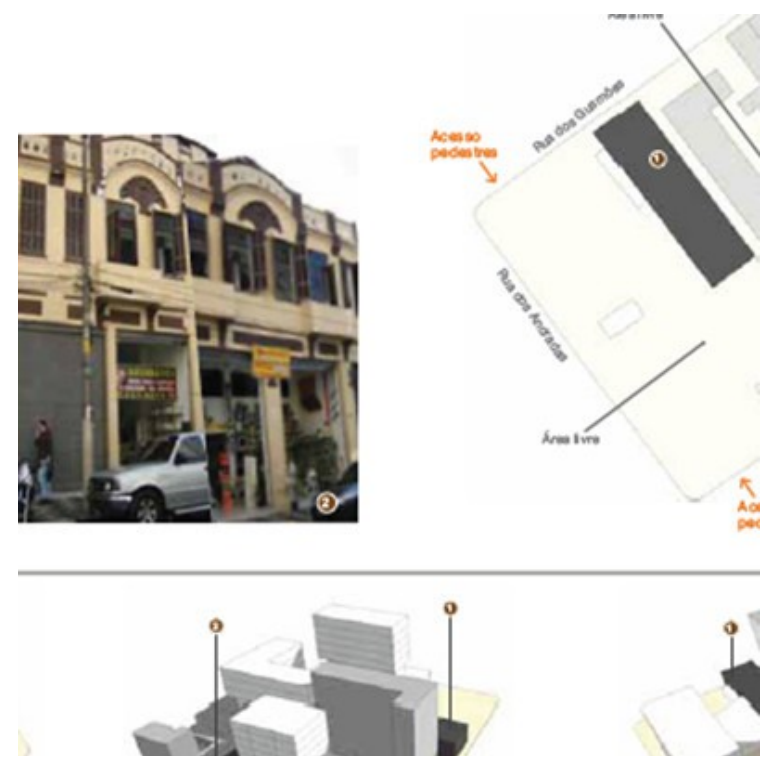

Figura 9 - Proposta para a quadra 75 do projeto Nova Luz, localizada na rua do Triunfo que inclui a demolição dos edifícios citados anteriormente (Soberado e Polydor) para substituílos por construções de uso residencial com até 30ml. Fonte: www.novaluz.com.br, disponível em 05/09/2012

A partir dos anos de 1980, a situação se alterou com a crise do cinema nacional, com o fim da exibição obrigatória de filmes nacionais e com a consolidação do cinema de sexo explícito, levando o modelo da "Boca" ao desaparecimento. Poucas 
empresas ligadas aos segmentos da indústria cultural permaneceram na área; muitas se deslocaram para o quadrante sudoeste da cidade, nas proximidades da marginal do rio Pinheiros (Vila Olímpia, Vila Madalena e Vila Leopoldina), acentuando o processo de degradação física e os problemas sociais existentes, em contraste com a prosperidade do comércio de eletroeletrônicos na rua de Santa Efigênia.

A situação de abandono das edificações, percebida a partir dos anos de 1970, manifestava-se também no espaço público, com ruas e praças sujas, malcuidadas e inseguras, demonstrando o descaso do poder público com a região - o que se acentuava nos horários em que o comércio estava fechado.

Mas o fator que mais contribuiu recentemente para consolidação da imagem negativa sobre o bairro foi o problema da dependência química, muito explorada pela mídia com o termo "Cracolândia" ${ }^{20}$, que acentuou o antigo estigma da região como "submundo" da cidade. A decadência física e os diversos problemas sociais presentes em Santa Efigênia desde o final do século XIX, tais como cortiços e prostituição, fizeram surgir expressões que denotam uma imagem negativa, como "Boca do Lixo", criada pela imprensa sensacionalista nos anos de 1950. Isto talvez justifique o fato de a PMSP ter se proposto a fazer uma "reinvenção" do bairro através do projeto Nova Luz, "rebatizando-o", como uma forma de ruptura com aspectos indesejáveis que ele apresenta, com o emprego do adjetivo "Novo", fazendo de Santa Efigênia uma extensão do polo cultural criado na década anterior. Novos usos, novos moradores, novos usuários, um suposto "novo", fictício, que seria capaz de se sobrepor ao existente, eliminando todas as marcas de sua história, como se isso fosse possível.

Apontado por seus críticos como instrumento de enobrecimento urbano, o Projeto Nova Luz foi rechaçado por moradores e comerciantes da região. Estes alegaram que não foram consultados quando da sua elaboração, o que determinou sua suspensão por parte do Tribunal de Justiça de São Paulo, em janeiro de 2013. Além disso, o projeto foi considerado ilegal por lesar os cofres públicos (já que o montante investido pela municipalidade seria muito maior do que o previsto para a iniciativa privada) e por favorecer a especulação imobiliária. 
Basicamente o movimento de oposição ao projeto se apresentava em dois grupos: o dos comerciantes e o dos moradores. O primeiro é composto por comerciantes ligados ao setor de eletroeletrônicos e de motopeças, e que se viram prejudicados pelo projeto por ele propor a substituição destas atividades pelas exercidas por grandes empresas de tecnologia da informação. Ao grupo dos comerciantes se juntaram os proprietários de grandes imóveis.

O outro grupo é formado pelos moradores do bairro. Estes se sentiam ameaçados pelo projeto por não terem nenhuma garantia de permanência, uma vez que não havia sido concluído o cadastramento dos moradores. A este grupo somaram-se os movimentos sociais que militam por moradia no Centro, e que ocupam diversos prédios que estavam abandonados na região. O mais conhecido e organizado é o movimento da Ocupação Mauá, cujos militantes estão instalados em um edifício diante da Estação da Luz. Foi a mobilização destes grupos que viabilizou a criação do Conselho Gestor das ZEIS do Projeto Nova Luz, em meados de 2011. Apesar de previsto como instância intermediária entre a sociedade civil e a municipalidade pela lei que criou o Nova Luz, tendo como objetivo possibilitar a participação da sociedade na elaboração do projeto, o Conselho foi criado depois que o projeto já havia sido apresentado publicamente, segundo a doutoranda Simone Gatti, urbanista do movimento AMOALUZ. Serviria assim como instância de legitimação de um projeto que já estaria pronto, o que não aconteceu dada a oposição e a vigilância dos moradores e dos comerciantes ${ }^{21}$.

Em alguns momentos esses movimentos sociais caminharam juntos; em outros, nem tanto. Porém, cabe destacar que nenhum dos dois grupos tem como pauta de discussão ou proposta de ação a questão da preservação ou do tombamento do bairro. O grupo dos moradores reconhece a listagem elaborada pelos órgãos preservacionistas, e que norteou o projeto Nova Luz, propondo a inclusão nesta lista de mais alguns edifícios reconhecidos por seu uso e memória afetiva, tais como o Bar do Léo e a uma antiga loja de instrumentos musicais.

A quase inexistência de mobilização em torno da questão da preservação parece ter algumas justificativas. A precariedade em que vivem alguns grupos de moradores 
(cortiços e ocupações) faz com que se dediquem à garantia da implementação das Zeis (Zonas Especiais de Interesse Social), previstas no plano diretor, e que representa uma possibilidade de melhoria nas condições de vida, mesmo que isto implique a demolição de bens culturais ${ }^{22}$. Parece impensável para os líderes dos movimentos a possibilidade da preservação das edificações e, concomitantemente, a implementação de políticas habitacionais abrangentes e eficazes, com o objetivo de garantir a permanência da população nas áreas a ser afetadas pelas intervenções, garantindo a autenticidade do ponto de vista do patrimônio edificado e da sociabilidade. Esta possibilidade não está no horizonte dos movimentos sociais. Nem tampouco do Estado que, em suas ações na região nas últimas décadas, tem demonstrado vínculo com uma concepção de cultura como entretenimento ou como erudição. Somando-se a isto devem-se considerar a "tradição" de autoritarismo e exclusão presentes na história da cidade de São Paulo, sobretudo ao longo do século XX, "tradição" esta caracterizada pela expulsão das camadas mais pobres para as periferias da cidade. O que seria um "jeito paulistano" de fazer cidade nas últimas décadas se vê reforçado e legitimado por modelos urbanos neoliberais adotados em cidades como Barcelona, Londres e Boston, modelos estes cuja aplicação tem como resultado o aumento da exclusão social, da fragmentação do tecido urbano e da supressão da cidadania.

\section{Um balanço}

Desde os anos de 1980, vários pensadores vêm apontando supostos perigos criados pelo crescente processo de mundialização da produção. O maior deles seria a homogeneização da cultura e de suas manifestações, sobretudo as cidades, espaços privilegiados que materializam a produção humana e que nas últimas décadas têm concentrado a maior parte da população mundial.

Passados os anos, esse temor foi atenuado, uma vez que o processo de homogeneização estimulou a acentuação das diferenças locais, principalmente nas grandes cidades. Seja como "estratégia" de governo ou empresarial, seja de modo mais livre ou espontâneo (se isto for possível), as particularidades de cada cidade, sua história, vocações, processos produtivos, cultura política e dinâmicas sociais, têm sido ressaltadas. Essas diferenças têm-se tornado, inclusive, mais evidentes 
nos estudos voltados para a elaboração de rankings das cidades globais, como demonstra Saskia Sassen (SASSEN; 2008).

Em São Paulo não seria diferente. Assim, tendências gerais do mundo contemporâneo, como a valorização da memória, analisada por Huyssen (HUYSSEN; 2000), ou a substituição do planejamento urbano pelo planejamento estratégico, estudado por Otília Arantes (ARANTES et al.; 2002), em São Paulo apresentam particularidades locais que merecem ser estudadas mais detidamente.

Nesse sentido, pudemos perceber que apesar de vivermos um contexto histórico pautado pela "cultura da memória", esta ainda sofre resistência em São Paulo, sobretudo quando se trata da paisagem urbana. Aqui, o imaginário ligado à ideia da cidade símbolo do progresso, "da cidade que não para", e de certo modelo de desenvolvimento pautado pelo rodoviarismo e pela verticalização ainda é muito forte, ecoando até hoje os valores e o ideário urbano dos anos de 1950. Daí a fragilidade das políticas de preservação, dada a inexistência (ou quase) de uma política associada ao planejamento urbano, e que atenda as necessidades da metrópole contemporânea.

Claro está que muitas mudanças ocorreram nas últimas décadas, já que a tabula rasa defendida pelo modernismo funcionalista (e que em São Paulo foi fartamente apropriado por setores ligados ao mercado imobiliário), já não é mais tão bem vista. Porém nem tanto assim. Muitos edifícios e áreas urbanas estão protegidos legalmente, mas a morosidade nos estudos do tombamento, a inexistência de uma política clara de incentivos fiscais aos proprietários, e a desvalorização dos imóveis com o tombamento acabam facilitando "a realização de grandes negócios imobiliários", leia-se demolição indiscriminada e verticalização. Vários exemplos têm sido noticiados recentemente, particularmente nas áreas das Operações Urbanas. Cabe lembrar que o setor imobiliário em São Paulo é considerado dos mais dinâmicos e lucrativos quando comparado a outras cidades do mundo (SASSEN; 2008).

Porém, tomando o caso de Santa Ifigênia como exemplo, vimos que a questão da preservação, ou melhor, do tombamento, é até considerada por alguns segmentos 
sociais, mas é ainda uma visão muito limitada. O tombamento, quando ocorre, deve estar restrito a edificações que facilitem a compreensão de uma determinada visão de história, capaz de eliminar contradições, tensões e resistências, criando uma versão anacrônica, idealizada e de fácil compreensão para visitantes desavisados. Tal postura tem se mostrado oportuna e complementar à viabilização de "negócios urbanos" ligados ao mercado imobiliário e ao turismo.

Diante de tal horizonte, em São Paulo, a participação dos movimentos sociais têm sido uma constante, na medida em que a permanência no lugar onde vivem e a possibilidade de melhora na condição de vida tem sido violentamente ameaçada. Aqui, porém, diferente de outras cidades brasileiras, o apreço ao lugar, à paisagem, aos costumes e ao modo de vida do bairro, não tem mobilizado esses grupos no sentido da preservação do ambiente físico na região de Santa Efigênia. Ao contrário. As condições precárias em que vivem, o problema da dependência química, sintetizada na expressão "Cracolândia", tem minado qualquer sinal de "orgulho cívico" ou senso de pertencimento. Esta situação talvez justifique o fato de não proporem a preservação, com a reforma das edificações deterioradas para a habitação da população local. Defendem, sim, a implementação das Zeis (Zonas Especiais de Interesse Social), com a construção de edifícios de habitação multifamiliar.

A posição dos comerciantes e proprietários de imóveis não é muito diferente no que se refere ao patrimônio. Mesmo estabelecidos no bairro há décadas, não se detém a questão da preservação da paisagem como pauta de reivindicação, procurando formas de ação que respeitem as leis de preservação vigentes, mas que permitam a máxima lucratividade na exploração do espaço.

Nesta pesquisa estamos trabalhando com a hipótese de que está havendo o "esquecimento" de aspectos da história da cidade de São Paulo, em toda a região central, particularmente na região de Santa Efigênia, aspectos estes que ressaltam as contradições, os conflitos, as tensões de um processo de urbanização violento, permeado por desigualdade e injustiça social. Estas tensões deixaram "marcas" na região através do "submundo da Boca do Lixo", marcado pela prostituição, pela precariedade dos cortiços, pela verticalização de edifícios de quitinetes, e na 
precariedade do cinema da Boca. Estes aspectos da história do bairro, contudo, permanecem dispersos e fragmentados, abordados por estudiosos do cinema paulistano por teses, livros, artigos, entrevistas, fotos, documentários etc., o que garante a informação sobre esta realidade. Porém, no que se refere ao patrimônio edificado e às políticas culturais oficiais, nada foi considerado legítimo para a memória da cidade, nem os aspectos ligados a migração e a imigração, nem a indústria cultural, nem ligados às transformações nos modos de morar, nem ao tipo de sociabilidade mista, tensa, heterogênea que se dá na região.

Considerando que a maioria dos espaços e das pessoas que vivem ali está ligada diretamente ou indiretamente ao que vai ser "esquecido", cabe questionar se será possível a construção de uma "memória viva". Esta, segundo definição de Huyssen "é ativa, viva, incorporada no social - isto é, em indivíduos, famílias, grupos, nações e regiões. Estas são as memórias necessárias para construir futuros locais diferenciados num mundo global" (HUYSSEN; 2000, p. 37)

\section{Notas}

(1) Estudo minucioso sobre o assunto foi feito por Beatriz Kara-José em Políticas culturais e negócios urbanos: a instrumentalização da cultura na revitalização do Centro de São Paulo 1975-2000. São Paulo, AnnaBlume/Fapesp, 2007.

(2) Tivemos acesso aos processos de tombamento de alguns edifícios (Estação da Luz e Júlio Prestes), porém não pudemos pesquisar o processo do bairro de Santa Efigênia por estar em uso pelo corpo técnico desde 2009, quando iniciamos esta pesquisa.

(3) Pudemos perceber através da mídia, particularmente a impressa, o jogo de forças e os interesses políticos e econômicos dos grupos sociais envolvidos com a região, inclusive os próprios meios de comunicação que, apesar de postura supostamente "neutra", têm se posicionado implicitamente no processo de requalificação da região.

(4) A pesquisa foi iniciada em 2009, e deste então vimos fizemos diversas entrevistas com moradores, proprietários ou não, comerciantes e frequentadores do bairro. No primeiro semestre de 2011, em função da realização do Seminário Internacional Políticas culturais, patrimônio edificado e intervenção urbana: perspectivas para a metrópole do século XIX, ocorrido nos dias 24, 25 e 26 de maio, no Centro Cultural Banco do Brasil, do qual fizemos a curadoria, tivemos a oportunidade de conversar com técnicos da administração pública envolvidos com o projeto Nova Luz, gestores públicos, acadêmicos, e lideranças de movimentos sociais que militam pela questão da moradia no Centro. 
(5) Referimo-nos, particularmente, ao caso do Rio de Janeiro, com a criação do projeto do "Corredor Cultural" (1984). Lilian Fessler Vaz, e Carmen Silveira,.A Lapa boêmia na cidade do Rio de Janeiro: um processo de regeneração cultural?, Projetos, intervenções e dinâmicas do lugar, em Ana Luisa Howard Castilho; Heliana Comin Vargas, Intervenções em centros urbanos: objetivos, estratégias e resultados, São Paulo, Manole. 2006.

(6) Não existem bairros clara e oficialmente delimitados em São Paulo. As denominações utilizadas ainda hoje são imprecisas, variando conforme o interlocutor. A cidade está oficialmente dividida em distritos, desde 1991, e Santa Efigênia faz parte do distrito República.

(7) Em linhas gerais, poderíamos apontar quatro momentos importantes para a ocupação da região: uma primeira fase, durante a segunda metade do século XVIII, com a criação da freguesia (1809) e construções ao longo dos caminhos que iam para o interior (Campinas e Sorocaba, sobretudo); um segundo momento, na segunda metade do século XIX, com a instalação da Estação São Paulo Railway e o loteamento do bairro, sendo o primeiro bairro com traçado reticular na cidade, com ruas retas e arborizadas, antecedendo o vizinho, Campos Elísios; terceira fase, nos anos de 1940 e 1950, com a implementação do Plano de Avenidas; quarta fase, a partir dos anos de 1970, com a crise da produção industrial e do Centro .

(8) Recentemente, o Ministério Público do Estado de São Paulo moveu uma ação civil pública contra o Governo do Estado, particularmente a Secretaria Estadual de Cultura, por que "contratou, iniciou e executou obras de reforma do prédio situado no Largo General Osório, 66, 86, 120 e 136, onde funcionou um dos mais notórios órgãos da repressão política do país, o extinto Departamento de Ordem Política e Social - DOPS/SP (ou DEOPS), e atualmente funciona o museu Estação Pinacoteca, [...], sem prévia autorização dos órgãos de proteção dos bens de interesse cultural no caso o Iphan, o Condephaat e o Conpresp, uma vez que o bem estava tombado ou em processo de tombamento por estes três órgãos. [...] a Requerida causou danos irreparáveis e irreversíveis ao referido bem e consequentemente ao povo paulista e brasileiro. Disponível em: <http://www.mp.sp.gov.br/portal/page/portal/noticias/publicacao noticias/2013/janeiro_2013/2013\%2001\%2010\% 20MP\%20pede\%20indenização\%20por\%20reforma\%20que\%20descaracterizou\%20a\%20Estação

\%20Pinacoteca.pdf> Acesso em: 10 jan. 2013.

(9) A proximidade entre terminais de transporte e grandes equipamentos culturais tornou-se solução recorrente nas últimas décadas nesta "nova" modalidade de planejamento urbano, tendo como referência o exemplo do Les Halles de Paris, considerado muito bem-sucedido. Décadas depois, observa-se a permanência deste ideário orientando ações na região da Luz/Santa Ifigênia, e justificando a criação do Museu da Língua Portuguesa: "Para o secretário da Cultura Marcos Mendonça, a implantação do centro cultural na Estação da Luz, articulado com o mais complexo terminal de transportes da região é um passo definitivo para a revitalização da área central da cidade. A recuperação de imóveis históricos e seu uso com finalidades culturais, lembra Mendonça, exercita as mais modernas teorias urbanísticas hoje em desenvolvimento na Europa e nos EUA. Nelas, "ancoras culturais" são utilizados para melhorar a qualidade de vida em áreas deterioradas" Revista Cultural. São Paulo, maio de 2001, p. 12.

(10) O uso da isenção fiscal para investimento de empresas na requalificação de patrimônio edificado tornou-se um paradigma nesses anos, não estando restrita apenas ao caso de São Paulo. Se retomarmos novamente o caso do Rio de Janeiro podemos destacar a participação de empresas públicas como o Banco do Brasil, que criou seu próprio centro cultural em área do "Corredor Cultural", e da Petrobras, que passou a financiar obras de restauro na área do "Distrito Cultural da Lapa", projeto criado em 2000, região que passou a ter grande visibilidade como centro de lazer noturno. 
(11) A justificativa para a adoção deste modelo se deve a suposta agilidade que ele confere, desde a compra de materiais, passando pela contratação de funcionários (sem concurso), até a captação de recursos, doações e de patrocínio, sendo a captação de recursos faz parte das metas do plano de trabalho da OS, devendo captar entre 5 a $10 \%$ do valor que o Estado repassa para a sua manutenção. Tal fato certamente justifique a preocupação com a visibilidade dessas instituições, pois é a única forma de garantir a afluência de recursos de patrocinadores.

(12) ARANTES, Otília. Uma estratégia fatal. A cultura nas novas gestões urbanas. Em Otília Arantes, Carlos Vainer; Ermínia. Maricato, $\underline{A}$ cidade do pensamento único: desmanchando consensos. Petrópolis: Vozes, 2000.

(13) Este era o perímetro inicial do projeto. Em 2010 a área do projeto foi ampliada, estendendo-se até a avenida São João, totalizando $45 \quad$ quadras. $\quad$ Disponível $\mathrm{em}$ <http://centrosp.prefeitura.sp.gov.br/projetos/novaluz_area.php>. Acesso em: 11 jun. 2009.

(14) Este era o argumento apresentado pelos proprietários dos imóveis nas entrevistas realizadas no início desta pesquisa, em 2009. A partir de 2011 a situação mudou consideravelmente, de modo que muitos imóveis propostos para o tombamento estão reformados e sendo utilizados como comércio (autopeças, eletrônicos, alimentação e instrumentos musicais) ou como estacionamentos. O receio diante da possível implementação do projeto Nova Luz, e da uma desapropriação desvantajosa, somada a expressiva valorização do metro quadrado na região nos últimos anos, podem explicar o fato.

(15) Folha de S. Paulo, 19/2/2010.

(16) Folha de S. Paulo, 19/2/2010.

(17) Meses antes havia sido aberta a licitação para a escolha do grupo de empresas responsáveis pela elaboração do projeto de intervenção para a área, dando continuidade ao processo de implementação da concessão urbanística Nova Luz, escolha esta divulgada em maio de 2011. A proposta vencedora foi a do grupo formado pela Fundação Getúlio Vargas (FGV), pela construtora Concremat, pela Companhia City e pela Aecom.

(18) Disponível em < www.novaluz.com.br> Acesso em: 5 set. 2012.

(19) Em pesquisa de campo realizada em janeiro de 2013, verificamos que dois terrenos de grandes dimensões, um localizado na Barão de Limeira n. 238 e outro com acessos pelas ruas Conselheiro Nébias n.262 e Vitória n. 595, funcionam como estacionamento,e constam como patrimônio histórico no Projeto Nova Luz. Disponível em: ,< www. Novaluz.com.br>. Acesso em: 5 set. 2012.

(20) Este termo, criado a partir dos anos de 1990, tem acentuado ainda mais a desvalorização do bairro e a proliferação de estereótipos e generalizações que criaram uma clima de emergência e pânico, induzindo a opinião pública a apoiar intervenções radicais, como o projeto Nova Luz.

(21) Simone Gatti,. Em busca de uma construção democrática no Projeto Nova Luz. São Paulo: CCBB, 25 de maio de 2011, entrevista a Herta Franco.

(22) Cabe lembrar que a área das ZEIS envolve a rua do Triunfo, onde há uma concentração de edificações em processo de tombamento, o que impossibilitaria a construção de habitações de interesse social. 


\section{Referenciais Bibliográficos:}

ARANTES, Otília (2000). Uma estratégia fatal. A cultura nas novas gestões urbanas. In: ARANTES, O., VAINER, Carlos e MARICATO, Erminia. A cidade do pensamento único: desmanchando consensos. Petrópolis: Editora Vozes, 2000.

CAMPOS, Candido Malta. Os rumos da cidade: urbanismo e modernização em São Paulo. São Paulo: Senac, 2002

CANCLINI, Nestor. O patrimônio cultural e a construção imaginária do nacional. In: Revista do IPHAN, n. 23, 1994. p. 94-115.

Cartas Patrimoniais. Disponível em <http://www.icomos.org.br> Acesso em: 20 jan. 2012.

CÉSAR, Roberto Cerqueira; FRANCO, Luiz Roberto Carvalho; BRUNA, Paulo Júlio Valentino. Área da Luz: renovação urbana em São Paulo. São Paulo; Secretaria da Cultura, Ciência e Tecnologia do Estado de São Paulo. São Paulo: Editora Perspectiva, 1977.

CHOAY, Françoise. A alegoria do patrimônio. São Paulo: Estação Liberdade/Unesp, 2006.

COELHO Jr, Márcio Novaes. Processos de intervenção urbana: bairro da Luz. Tese de doutorado pela. FAUUSP, São Paulo: 2010.

FABRIS, Annateresa (Org.). Ecletismo na arquitetura brasileira. São Paulo: Nobel/EDUSP, 1987.

FEATHERSTONE, Mike. Cultura de consumo e pós-modernismo. São Paulo; Nobel, 2007.

FELDMAN, Sarah. Segregações urbanas espaciais: a territorialização da prostituição feminina em São Paulo. Dissertação de mestrado, FAU-USP, São Paulo; 1989.

GATTI, Simone. Em busca de uma construção democrática no Projeto Nova Luz. [Trabalho inédito]

GUIRARDO, Diane. Arquitetura contemporânea: uma história concisa. São Paulo: Martins Fontes, 2002.

HARVEY, David. Do gerenciamento ao empresariamento: a transformação da administração urbana no capitalismo tardio. In: Espaço e debates: Revista de Estudos Regionais e Urbanos. São Paulo (39), 1996. p. 4864.

HUYSSEN, Andreas. Seduzidos pela memória: arquitetura, monumentos e mídia. Rio de Janeiro: Aeroplano Editora, 2000.

KARA-JOSĖ, Beatriz. Políticas culturais e negócios urbanos:_a instrumentalização da cultura na revitalização do Centro de São Paulo 1975-2000. São Paulo; Fapesp/Annablume, 2007. 
MONGIN, Olivier. A condição urbana: a cidade na era da globalização. São Paulo: Editora Estação Liberdade, 2009.

NOVA LUZ. Disponível em: <http://www.novaluzsp.com.br>. Acesso em: 30 agosto de 2012.

Revista Cultural. São Paulo, maio de 2001.

Revista Acrópole._São Paulo (36), 1941.

RODRIGUES, Marly. De quem é o patrimônio ? Um olhar sobre a prática preservacionista em São Paulo. In: Revista do patrimônio. Rio de Janeiro (24), 1996. p. 175-184.

RODRIGUES, Marly. Imagens do passado. A instituição do patrimônio em São Paulo, 1969-1987. São Paulo: Imesp: Unesp: Condephaat: Fapesp, 2000.

SASSEN, Saskia.. As diferentes especializações das cidades globais. Urban Age; dez. 2008.

SANTOS, M. V. M. Nasce a Academia SPHAN. Revista do Patrimônio Histórico e Artístico Nacional. n. 24, p.7796, 1996.

STERNHEIM, Alfredo. Cinema da Boca: dicionário de diretores. São Paulo: IMESP, 2005.

VAZ, Lilian. A "culturalização" do planejamento e da cidade: novos modelos? Cadernos PPG-AU/UFBA, vol. 3 edição especial 2004.

VAZ, Lilian Fessler e SILVEIRA, Carmen. A Lapa boêmia na cidade do Rio de Janeiro: um processo de regeneração cultural? Projetos, intervenções e dinâmicas do lugar. In: CASTILHO, Ana Luisa Howard; VARGAS, Heliana Comin; Intervenções em centros urbanos: objetivos, estratégias e resultados. São Paulo: Manole. 2006.

VIVA O CENTRO. Disponível em: <www.vivaocentro.org.br>. Acesso em $1^{\circ}$ jul. 2012.

\section{Créditos}

* Historiadora (FFLCH-USP), Doutora (FAU-USP), Professora titular Universidade Paulista hfnajm@uol.com.br Pesquisa financiada pela Universidade Paulista. 